\title{
Role of education and extension in the adoption of technology: a study of upland rice and soybean farmers in Central-West Brazil
}

\author{
John Strauss ${ }^{a}$, Mariza Barbosa ${ }^{b}$, Sonia Teixeira ${ }^{c}$, Duncan Thomas ${ }^{d}$ \\ and Raimundo Gomes Junior ${ }^{\mathrm{b}}$ \\ ${ }^{a}$ Rand Corporation, 1700 Main Street, Santa Monica, CA 90406, USA \\ ${ }^{b}$ EMBRAPA-SEP, Parque Rural, 70770 Brasilia, DF, Brazil \\ ${ }^{c}$ FMBRA PA Centro Nacional de Pesquisa de Arroz e Fejao (CNPAF), Caixa Postal 179, \\ 74000 Goiania, GO, Brazil \\ ${ }^{d}$ Yale University, P.O. Box 1987 Yale Station, New Haven, CT 06520, USA
}

(Accepted 15 June 1990)

\begin{abstract}
Strauss, J., Barbosa, M., Teixeira, S., Thomas, D. and Junior, R.G., 1991. Role of education and extension in the adoption of technology: a study of upland rice and soybean farmers in Central-West Brazil. Agric. Econ., 5: 341-359.

This paper explores reduced form determinants of the adoption of certain technologies by upland rice and soybean farmers in the Center-West region of Brazil. We merge community level data on the availability and quality of publicly provided infrastructure, principally extension, to the farm level data containing information on farmer human capital as well as land quantity and quality. By using community level measures of availability and quality of extension, we avoid problems of endogeneity of farm level measures of extension use. We find positive impacts of farmer education on the diffusion process, in accordance with other studies. We also isolate effects of the quality in regional extension investment as measured by the average experience of technical extension staff. These results indicate that investments in human capital of extension workers does have a payoff in terms of farmer adoption of improved cultivation practices.
\end{abstract}

\section{INTRODUCTION}

Since 1974 the Brazilian government has invested considerable resources in agricultural research. The knowledge which has been accumulated, and the technologies which are available, have been adopted by farmers only with a considerable lag. Furthermore, this lag is not the same for all products, for all farmers, for all communities or for all regions.

Several factors, including structural transformations in the Brazilian econ-

0169-5150/91/\$03.50 $\quad$ (C) 1991 - Elsevier Science Publishers B.V. 
omy and different agricultural policies, probably contribute to this gap in technology adoption. We focus in this paper on two factors which are important from a public policy point of view: the education of the farmer, and the availability and quality of extension services. Education has been widely discussed as an important determinant of production efficiency and technology diffusion (e.g., Welch, 1970; Jamison and Lau, 1982; Feder et al., 1985). There are fewer studies of the impact of extension [see Birkhauser et al. (1991) for a survey and Patrick and Kehrberg (1973) for a study of Brazilian agriculture]; many of these studies have failed to account for the fact that measures of farm level extension contacts should be treated as endogenous and even fewer explicitly account for the quality of extension services. We address both issues.

Heterogeneity in the regional composition of agriculture within Brazil has been explained, in part, by the availability of technology for different crops (Homem de Melo, 1983). We will examine the adoption of a series of technologies by rice and soybean farmers in Goias, Matto Grosso and Matto Grosso do Sul, the three states in the Brazilian Center-West. Since the late 1970 s, this region has been a large contributer to agricultural production in Brazil and, at present, the Center-West accounts for about a third of the total national area planted with rice, over a quarter of the area planted with soybeans and nearly a fifth of the land planted with rice, soybeans, beans, corn and wheat taken together. Regional yields are higher than the Brazilian averages for soybeans, corn, cassava, cotton and sugar cane; they are lower for wheat and rice, but this is because the all-Brazil average includes irrigated land of which there is little in the Center-West.

There have been substantial changes in the allocation of land to different crops over the last two decades in Brazil. Perhaps one of the most dramatic, and important, events in this process of change is the sixfold increase of the area planted with soybeans in the Center-West over the last decade. Upland rice, which is a traditional crop in this area, ${ }^{1}$ tends to be cultivated by farmers who recently migrated to the Center-West. The area planted with rice rose substantially from $1970 / 71$ through to the end of that decade and has continued to rise since $1985 / 6$ when it pulled out of a stagnant period during the early 1980s (Teixeira, 1987).

Using data collected by the Centro Nacional de Pesquisa de Arroz e Feijao (CNPAF) in 1985/86, we will study the determinants of the adoption of a series of technologies and cultural practices by upland rice and soybean farmers. Both soybeans and upland rice technologies began to be introduced

\footnotetext{
$\overline{1}$ It has been historically cultivated as a way of correcting soil before turning the land to pasture.
} 
in the region after 1980. Since no retrospective information was collected in the survey, we are unable to model the dynamics of the diffusion process. We therefore study how the adoption and extent of adoption, of a set of practices at one point in time are affected by farm and farmer characteristics, together with the availability and quality of publicly provided infrastructure.

We find, as in other studies, that farmer's education positively affects the adoption of new technology. We isolate effects of the quality of regional extension investment as measured by the average experience of technical extension staff. These results, which are new to the agriculture diffusion literature, indicate that investments in human capital of extension workers does have a payoff in terms of the adoption of better cultivation practices by farmers.

\section{METHODOLOGY}

We view the adoption of technology as an economic decision based on discounted expected marginal benefits and costs. The empirical specification used in this paper is consistent with a variety of models of farmer or farm household optimization: maximizing expected profits, expected utility of profits or expected utility of consumption and leisure subject to production function and time constraints (see Roe and Graham-Tomasi, 1986). For convenience in exposition, let us take the first alternative. Discounted expected profits, $V(\cdot)$, will be composed of two parts: the difference in discounted expected value of production of all crops and livestock with and without adoption of the particular technology, minus the difference in costs. We can think of this as the difference of two profit functions, each of which is a function of the base year constraints and information of farmers. The constraint and information sets include four components; two at the farm level and two at the community levels. At the farm level we view as constraints, firstly, human capital factors associated with the farm decision making process and, secondly, wealth factors including the quantity and quality of land owned. We view land cultivated (which includes land owned) and other quasi-fixed factors, such as machinery, as adjustable over the time horizon of the farmer, and therefore do not include them as exogenous or pre-determined covariates. At the community level, the information set includes the level of farm services, especially extension and input marketing services; and agro-climate factors related to yield levels and instability.

Two types of human capital, education and experience, are plausibly related to technology adoption. All else equal, both should be positively related to information available to the farmer. Experience may provide general farming knowledge as well as specific knowledge about his or her 
particular farm, while education may enable the farmer to better process the information provided by different sources, and may increase both the allocative and technical efficiency of the farmer (Jamison and Lau, 1982). We assume all farming decisions are made by the household head and use his (or her) years of education as our measure of education, his age as a measure of general farming experience, and the number of years he has lived in the region as a measure of more region-specific experience. We would prefer to use the amount of time the farmer has been farming in the area; unfortunately this information is not available. It would also be useful to distinguish different types of education (such as technical and non-technical schools) but this information was not collected.

Since much land is rented, the amount of land cultivated is an input over which farmers have choice, even in the short run, and so it does not belong in a reduced form model. We include, therefore, the amount of land owned by the farmer, which is an indicator of wealth. One may argue that, in the long run, land sales are possible; we take a more medium run perspective here, while recognizing that larger farms may result from better managerial ability. The survey provides us with two types of variables relating to farm level land quality; the topography of the land (before any leveling or terracing is undertaken) and the degree of soil erosion. Both are somewhat crude measures; it might have been useful to have more precise data [see for instance Sidhu and Baanante (1981) or Bhalla (1988) for examples of input demand and yield analyses which indicate the usefulness of good land quality data].

Previous studies of farm technology adoption have used similar specifications; farmer education is almost always included, although experience measures other than age are seldom available; sometimes land quality data are also included. It is unusual, however, to find studies that use community level variables other than prices. We would argue, however, that the availability and quality of extension input provision and marketing services probably influence the adoption process, as do agro-climatic variables such as rainfall distribution [see Birkhauser et al. (1991) for a survey of the extension impact literature]. We take two approaches to modeling community influences.

We first include microregion-level dummy variables to capture these effects in an arbitrarily general way; these are fixed effect estimates. Secondly, we include variables designed to measure the community factors directly. $^{2}$

\footnotetext{
$\overline{2}$ We cannot hope to capture all factors which influence farmer decisions; what we hope to do is identify among these factors, those which have a large influence on technology adoption.
} 
Among the community factors, we include 'municipio'-level mcan and standard deviations of rice and soybean yields. These are derived from 7 years of data on municipio-level rice and soybean area and production. The source is independent of the sample, so there are no artificial correlations arising from data construction. Yields reflect, in part, past adoption of technology. They also reflect underlying agro-climatic potential, which will itself affect technology adoption. We use aggregate, municipio-level yield measures to capture municipio effects which may be correlated with farmlevel adoption. By doing so we reduce problems of endogeneity that would be greater if we used farm-level yields.

A second set of variables attempts to measure the level of services available to formers. We do not use information at the farm level, such as whether he or she has regular visits from an extension agent, because this would be endogenous in our model. In particular extension visits may arise because both the agent and the farmer want them. Agents may go to better farm managers on better land (or land closer to their offices) so as to maximize their impact. Provided there is useful information to extend there is likely to be more demand for it by better farmers on better endowed land. Thus inclusion of a farm level variable on extension contact is likely to give an upward biased coefficient on extension, as well as biasing downwards the education, experience and land quality coefficients. This may explain the positive extension and negative education effects reported in the study of Brazilian agriculture by Patrick and Kehrberg (1973).

The availability and quality of extension and other services at the community level may be more plausibly taken as exogenous to farmers. We have gathered, independently from the farm survey, municipio level data on the number of EMATER (Empresa Assistencia Technica Rurale - a state-level extension agency) technicians, their average experience in EMATER and the proportion who have at least a BS degree. In addition we have collected information on whether the municipio is served by a cooperative or a radio diffusion program, whether storage facilities are available (from CIBRAZEM - a public storage agency), and the number of banks which serve the municipio.

Based on the sample, we construct the percentage of farmers who have contact with FMBRAPA (Fmpresa Brasiliera de Pesquisa Agropecuaria the national agricultural research agency). Since there are too few sample observations in each municipio to use that as a meaningful level of aggregation, we define this variable at the larger microregion level. ${ }^{3}$

Theory suggests prices should also enter the reduced form. Unfortunately we only have data on prices at the state level; since the survey covers three

\footnotetext{
$\overline{3}$ Seven microregions are represented.
} 
states, there are not enough degrees of freedom to estimate price effects. To the extent that prices are correlated with observed farm and community characteristics, these estimates will be biased by the omission of prices although the fixed effects estimates (which include micro-region controls) will not be contaminated.

Having defined our variables we can outline the statistical model. Let

$V_{i \mathrm{~A}}=X_{i} \beta_{\mathrm{A}}+\varepsilon_{i \mathrm{~A}}$

be the discounted expected profits function using the adopted technology for the $i$ th farm, where $X_{i}$ is a vector of characteristics defined above and $\varepsilon_{i}$ is a random error. Let

$V_{i \mathrm{~N}}=X_{i} \beta_{\mathrm{N}}+\varepsilon_{i \mathrm{~N}}$

be discounted expected profits without the new practice. Let $V_{i}=V_{i \mathrm{~A}}-V_{i \mathrm{~N}}$, then if $V_{i}>0$ the technology or cultural practice is adopted, and not if $V_{i}<0$. Note that we consider each practice separately. We do not observed $V_{i}$ and $\varepsilon_{i}$ but we do observe both $X_{i}$ and whether the practice is adopted or not. Let $D_{i}=1$ if the practice is adopted, that is if $V_{i}>0$, then we have a standard model of qualitative choice. If $\varepsilon_{i}$ is assumed to be a Gaussian random variate with mean zero and unit variance, then the statistical model is a probit and can be estimated by maximum likelihood. Two dependent variables are continuous ${ }^{4}$ and are fitted by the method of least squares.

\section{DESCRIPTION OF DATA}

The data are drawn from a survey of rice and soybean farmers in the Center-West conducted at CNPAF (Teixeira, 1987; Barbosa and Teixeira, 1987). Its main purpose was to explain, at the farm level, the reasons for the expansion of soybeans, sometimes at the expense of food crops such as rice, and to characterize the forms of production. The sample regions were selected based on total acreage and production data for the two crops from 1973 to 1984 . The municipios were selected based on the increase over time of soybeans area and the decrease during the 1980's of rice areas. Two hundred farmers were surveyed, of which complete data (including community data on infrastructure) are available for 161 farmers. Of these, $50 \%$ are in Goias, and 25\% each in Mato Grosso and Mato Grosso do Sul. Additional data, collected at the municipio level, characterize the level of infrastructure in the agricultural sector; these include information on storage and banking

\footnotetext{
$\overline{4}$ They are an index of technology adoption and fertilizer use per hectare. Since almost all farmers use some fertilizer, data censoring at zero is not a problem.
} 
TABLE 1

Farm and farmer characteristics stratified by amount of land owned

\begin{tabular}{|c|c|c|c|c|}
\hline & \multirow[t]{2}{*}{ All } & \multicolumn{3}{|c|}{ Amount of land owned (ha) } \\
\hline & & $0-100$ & $101-500$ & $>500$ \\
\hline Proportion of farms & & $31 \%$ & $36 \%$ & $33 \%$ \\
\hline \multicolumn{5}{|l|}{ Area (ha) } \\
\hline Owned & $\begin{array}{c}590.4 \\
{[947.1]}\end{array}$ & $\begin{array}{c}12.0 \\
{[26.5]}\end{array}$ & $\begin{array}{c}267.8 \\
{[110.3]}\end{array}$ & $\begin{array}{c}1472.4 \\
{[1220.3]}\end{array}$ \\
\hline Cultivable & $\begin{array}{c}739.1 \\
{[950.3]}\end{array}$ & $\begin{array}{c}359.1 \\
{[382.9]}\end{array}$ & $\begin{array}{c}350.8 \\
{[255.0]}\end{array}$ & $\begin{array}{c}1486.9 \\
{[1277.5]}\end{array}$ \\
\hline \multicolumn{5}{|l|}{ Percent of area cultivable } \\
\hline soybeans & $\begin{array}{c}48.9 \\
{[32.8]}\end{array}$ & $\begin{array}{c}60.8 \\
{[36.6]}\end{array}$ & $\begin{array}{c}49.8 \\
{[27.4]}\end{array}$ & $\begin{array}{c}48.9 \\
{[32.8]}\end{array}$ \\
\hline rice & $\begin{array}{c}8.1 \\
{[13.6]}\end{array}$ & $\begin{array}{c}10.6 \\
{[17.8]}\end{array}$ & $\begin{array}{c}7.9 \\
{[13.5]}\end{array}$ & $\begin{array}{c}6.1 \\
{[8.4]}\end{array}$ \\
\hline corn & $\begin{array}{c}6.5 \\
{[13.7]}\end{array}$ & $\begin{array}{c}8.1 \\
{[18.9]}\end{array}$ & $\begin{array}{c}6.3 \\
{[11.0]}\end{array}$ & $\begin{array}{r}6.5 \\
{[13.7]}\end{array}$ \\
\hline Permanent crops and pasture & $\begin{array}{c}13.4 \\
{[22.2]}\end{array}$ & $\begin{array}{c}7.1 \\
{[16.9]}\end{array}$ & $\begin{array}{c}12.9 \\
{[20.7]}\end{array}$ & $\begin{array}{c}19.5 \\
{[26.2]}\end{array}$ \\
\hline Other & $\begin{array}{c}23.1 \\
{[28.1]}\end{array}$ & $\begin{array}{c}13.4 \\
{[27.7]}\end{array}$ & $\begin{array}{c}23.1 \\
{[24.0]}\end{array}$ & $\begin{array}{c}31.6 \\
{[30.1]}\end{array}$ \\
\hline \multicolumn{5}{|l|}{ Yield (kg/ha) } \\
\hline soybeans & $\begin{array}{l}1956.6 \\
{[728.2]}\end{array}$ & $\begin{array}{c}1990.3 \\
{[1052.6]}\end{array}$ & $\begin{array}{l}1863.3 \\
{[450.8]}\end{array}$ & $\begin{array}{l}2041.6 \\
{[631.2]}\end{array}$ \\
\hline rice & $\begin{array}{l}1367.6 \\
{[784.4]}\end{array}$ & $\begin{array}{l}1568.1 \\
{[774.3]}\end{array}$ & $\begin{array}{l}1345.4 \\
{[761.6]}\end{array}$ & $\begin{array}{l}1242.0 \\
{[805.0]}\end{array}$ \\
\hline \multicolumn{5}{|l|}{ Farmer characteristics } \\
\hline Farmer's age & $\begin{array}{c}38.1 \\
{[11.1]}\end{array}$ & $\begin{array}{l}35.9 \\
{[9.8]}\end{array}$ & $\begin{array}{c}38.0 \\
{[10.4]}\end{array}$ & $\begin{array}{c}40.1 \\
{[12.5]}\end{array}$ \\
\hline \multicolumn{5}{|l|}{ Experience in region } \\
\hline$\%<5$ years & 39.5 & 62.0 & 31.0 & 27.8 \\
\hline$\% 5-10$ years & 21.0 & 10.0 & 24.1 & 27.8 \\
\hline$\%>10$ years & 39.5 & 28.0 & 44.8 & 44.4 \\
\hline \multicolumn{5}{|l|}{ Education } \\
\hline$\%<4$ years & 56.8 & 60.0 & 55.2 & 55.6 \\
\hline$\%$ 4-8 years & 29.0 & 30.0 & 29.3 & 27.8 \\
\hline$\%>8$ years & 14.2 & 10.0 & 15.5 & 16.7 \\
\hline
\end{tabular}

Table based on date from 161 farms. Standard deviations in [parentheses]. Cultivable areas include area owned, plus rented-in land less rented-out land. Other land includes native fields, forests and unproductive land. 


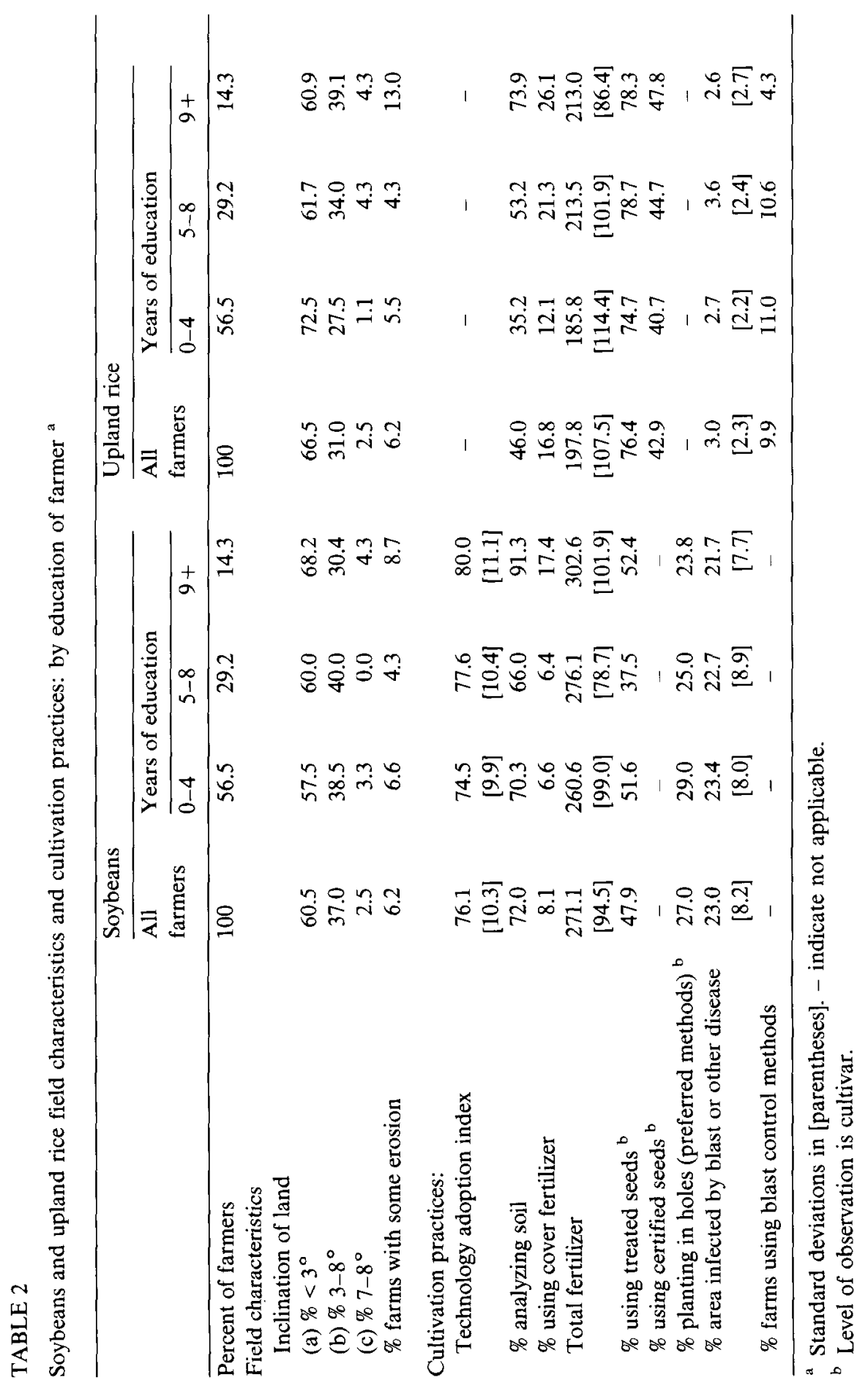


facilities, extension and education services, as well as a time series on area planted and production of rice and soybeans.

Table 1 shows that farms in the Center-West are large: the average farmer owns about 590 ha of land which is a little under $80 \%$ of the land he farms. The proportion of land rented falls with the size of the farm owned (but remains remarkably stable across the distribution of farms operated). Farms tend to be slightly larger in Mato Grosso do Sul. The majority of the land on the sample farms is planted with soybeans; among farmers who own less than 100 hectares of land, soybean cultivation accounts for about $60 \%$ of their farms but around one-half of farms operated by the larger landowners. Rice accounts for about $8 \%$ of the farmed land and that proportion also declines with the amount of land owned by the farmer. The proportion of farmland given to pastures and fields rises with farmer wealth and accounts for one fifth of the farm area of larger landholders. Forest and unproductive land is much less prevalent on land of small farmers; these farmers rent land almost exclusively for planting annual crops. Soybean yields, which are higher than rice yields, show little pattern across the distribution of landowners; rice yields on farms of small landowners are about a quarter larger than those of large landowners.

Most of the farmers in the sample are migrants from other regions in Brazil, particularly the South, and $60 \%$ of them have moved to the CenterWest in the last 10 years. Farmers who own more land tend to be older, have more experience in these frontier areas and have more education. The relationships between land owned and age, experience and education are non-linear: farmers who own less than 100 ha (one-third of the sample) have much less experience in the Center-West and also less education. The pattern of experience suggests that farmers are buying more land the longer they stay in the region.

For both soybeans and upland rice, the characteristics of fields used and the frequency of adoption of various cultural practices and technologies, are reported in Table 2 for all farmers and stratified by three farmer education levels. Overall field characteristics are similar for the two crops. Upland rice is more likely to be grown on flatter lands; less educated farmers tend to plant upland rice on flatter land and better educated farmers tend to plant soybeans on flatter land.

Soil analysis is more prevalent on soybeans fields. Use of some fertilizer is nearly universal, however use of cover fertilizer is not. Almost one half of soy plantings make use of seeds innoculated for nitrogen fixation capabilities and about three-quarters of rice seeds are treated for disease. Almost half the rice plots are planted with seeds which are certified by the Ministry of Agriculture and distributed by cooperatives and private firms. Soybean seeds are planted in holes (the preferred method) on about a third of the 
plots. Fifteen percent of the area planted to rice had blast problems and some $10 \%$ of farmers treat their fields for blast.

For many cultural practices, better educated farmers adopt practices which are preferred by agricultural researchers and extensionists. For both rice and soybeans, better educated farmers are more likely to analyze the soil, use cover fertilizer, use more of all fertilizer types per hectare and are more likely to use treated seeds. The better educated farmers are more likely to use certified rice seed.

Agronomists at CNPAF and CPAC (Centro de Pesquisa Agropecuaria do Cerrado) have assigned a score to each soybean farmer based on the appropriateness of the package of technologies chosen. Not surprisingly, better educated farmers tend to score better on this index (out of 100) although there is a large standard deviation around the mean.

Table 3 provides means and standard deviations of farmer access to community infrastructure. Each municipio has, on average, just under four EMATER technicians, each of whom has, on average, eight years of experience in the Center-West region and two of whom are likely to have a Bachelor degree. Average regional experience of extension agents within a municipio ranges from one year to fifteen. There are about five banks in each municipio, some municipios having none; the majority are served by a co-operative and have access to CIBRAZEM storage facilities although only a third receive diffusion information by radio. Over the previous six years,

TABLE 3

Means of community infrastructure variables

\begin{tabular}{lr}
\hline EMATER technicians (number) & 3.83 \\
& {$[1.2]$} \\
Average years of experience & 8.30 \\
& {$[2.9]$} \\
Proportion with B.S. degrees & 0.60 \\
& {$[0.3]$} \\
(1) if municipio has co-operative & 0.75 \\
radio diffussion program & 0.39 \\
CIBRAZEM storage facilities & 0.60 \\
Number of banks & 5.59 \\
& {$[2.7]$} \\
Soybean yields (1979/80-1985/6) & 1.44 \\
mean & {$[0.49]$} \\
standard deviation & \\
Rice yields (1979/80-1985/6) & 1.10 \\
mean & {$[0.30]$} \\
standard deviation &
\end{tabular}

Standard deviations in [parentheses]. 
the mean and variance of soybean yields were about $25 \%$ higher than the rice yields in the region.

\section{TECHNOLOGY AND CULTURAL PRACTICES: REGRESSION RESULTS}

Not all of the technology information collected in the survey is used in the regression analysis. Some practices are adopted by almost everyone and others by very few farmers; for these, there is no variation to explain. Some practices, such as use of herbicides for soybean farmers, are very hard to explain with the covariates we use; others are sufficiently close to those we do report that they provide no additional information. We focus on nine practices, five for upland rice and four for soybeans. They are whether the farmer does soil analysis (for both rice and soybean fields); whether the farmer uses certified rice seed or innoculated soybean seed; whether he uses cover fertilizer (for rice) and total fertilizer usage per hectare (for rice and soybeans); whether action is taken against rice blast (brusone); whether soybean fields are planted in (preferred) holes (or whether rows are used). Each dependent variable is estimated in isolation; these regressions cannot, therefore, take account of complementarities in technological practices. We include the CNPAF agronomists' index of soybean cultural practices as the tenth dependent variable, treating it as a continuous dependent variable. Relying on this index alone is unlikely to be a good empirical strategy; we therefore consider it in conjunction with the regressions explaining the adoption of individual practices.

The regression results, presented in Tables 4.1 and 4.2 for soybean and rice cultivation respectively, are discussed by group of covariates. The microregion-fixed effects estimates are in the first column of each pair; the community-level characteristics are included in the second column. We discuss, firstly, the effect of farmer human capital on the dependent variables, secondly, the effect of farm-level land quantity and quality variables, thirdly the extension availability and quality variables, and finally the community-level agro-climatic and infrastructure variables.

\section{Farmer education and experience effects}

Education of the farm operator has a positive effect, significant at the $10 \%$ level, in six of the ten regressions with microregion fixed effects and in four when municipio level covariates replace the microregion dummies. The overall index of soy cultivation practices rises six-tenths of a point for each year of education. Part of this reflects that better educated soybean farmers use more fertilizer (per ha). Better educated rice cultivators are more likely to do soil analysis and use cover fertilizer. All of these effects are robust to 


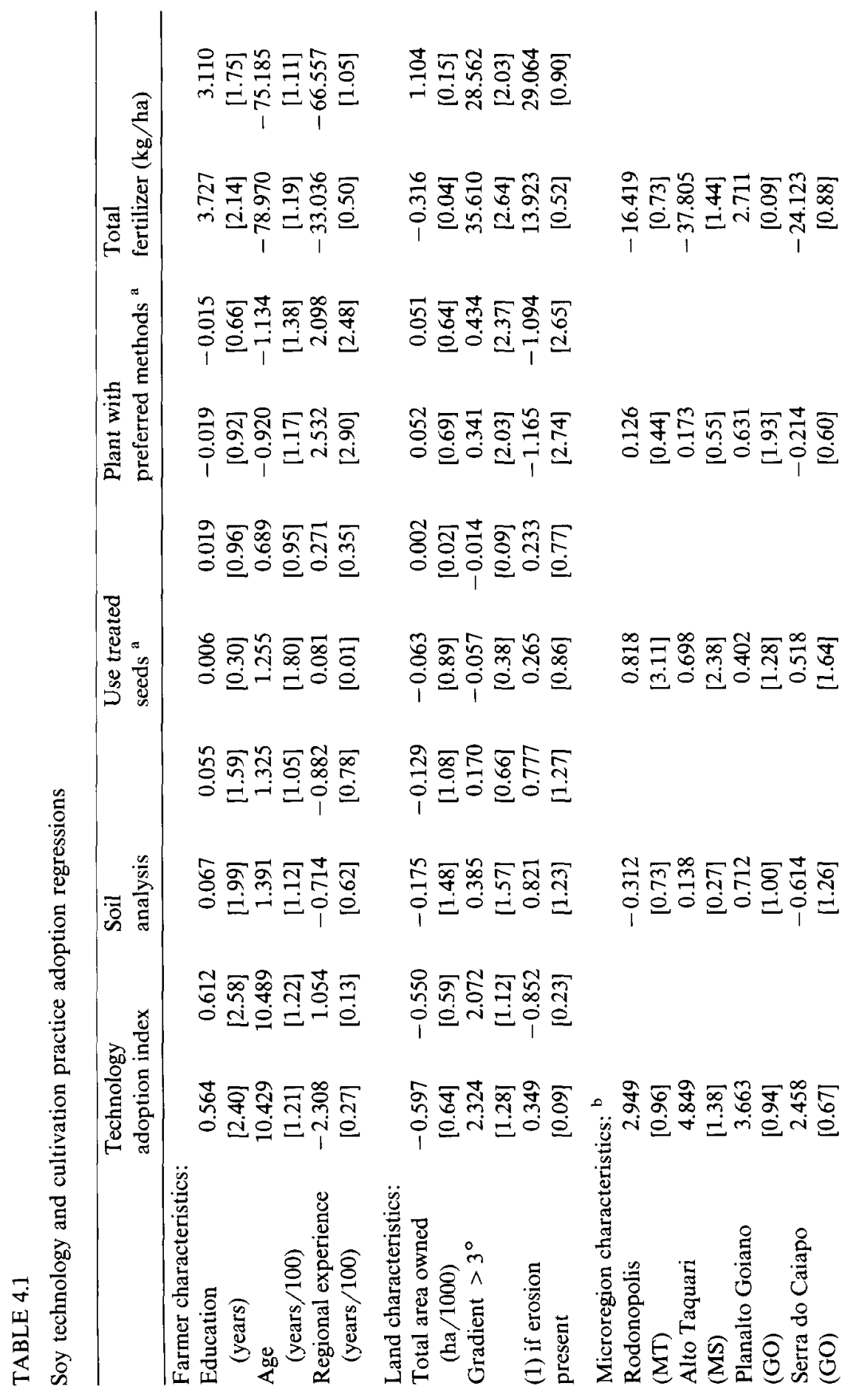




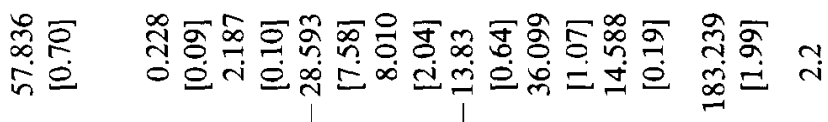

$\infty \underset{\sim}{\infty} \stackrel{\infty}{\dot{\sim}}$

$\infty \beth m i$

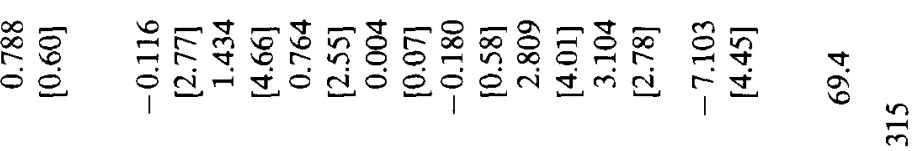

寻宁

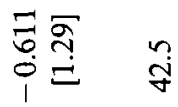

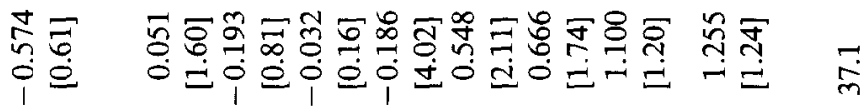

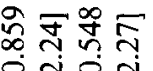

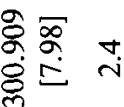

$0 \beth 0$ i

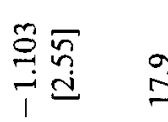

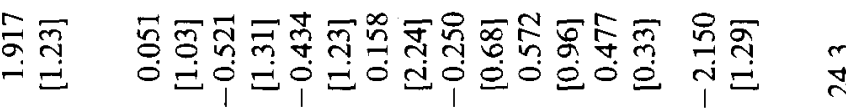

若灾导

$7=0$

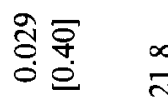

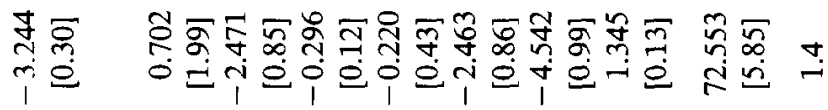

으ㅇㅠㅠ

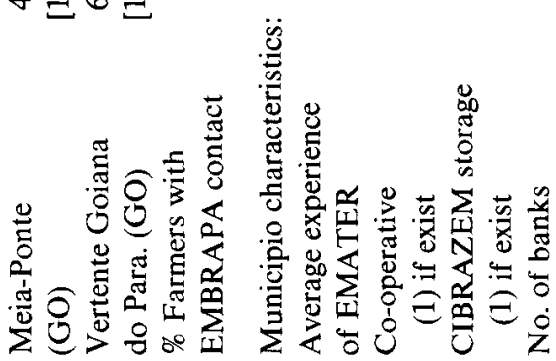

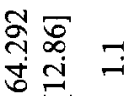

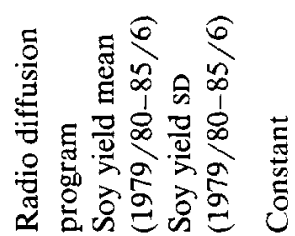

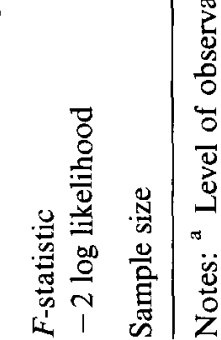




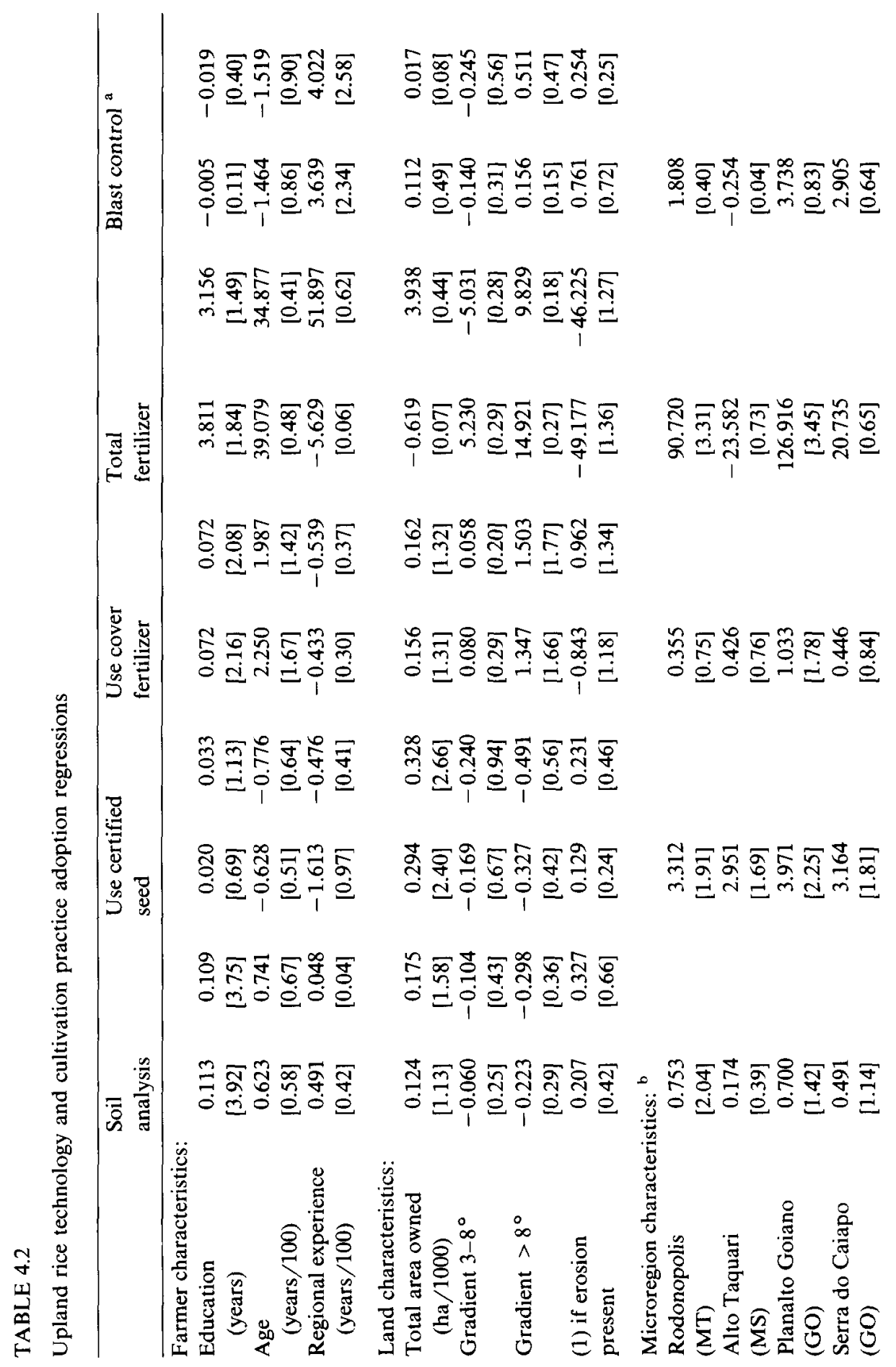




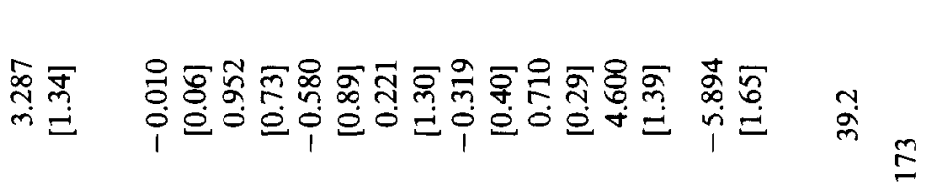

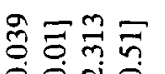

$$
\begin{aligned}
& i \text { i穴政 }
\end{aligned}
$$

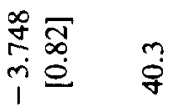

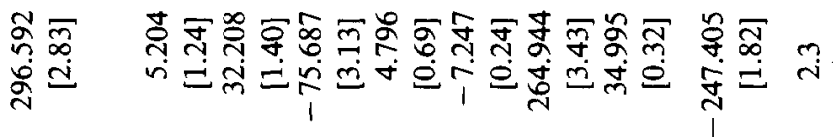

$$
\begin{aligned}
& \text { กั๊ } \\
& \text { 通丵 }
\end{aligned}
$$

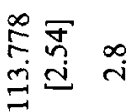

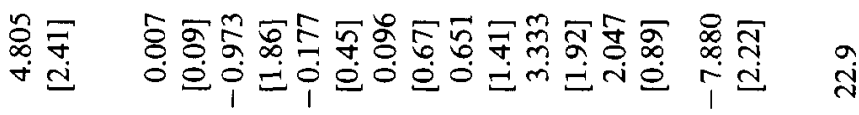

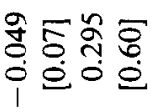

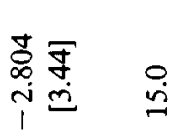

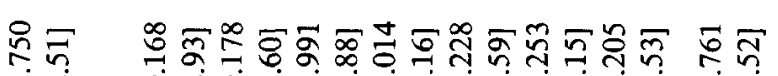

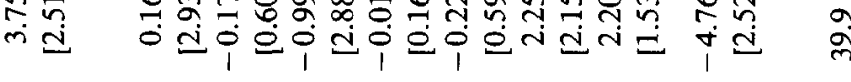

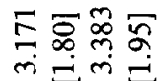

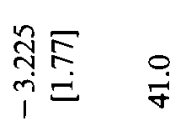

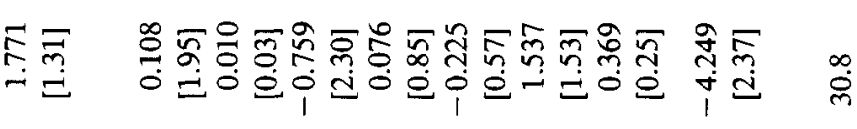


the inclusion of either region dummy variables or region-specific characteristics. Education has a significant positive effect only in the micro-region fixed effects regressions in two cases: the probability of doing soil analysis for soybean farmers and the amount of fertilizer used by rice farmers. This difference in results between the two specifications suggests that there may be interaction effects between education and community infrastructure; no interactions, however, are statistically significant in the regressions using region characteristics.

The age of the farmer, which is assumed to be a proxy for general experience, does not explain any of the adoption patterns. Time spent in the current region of residence is, however, strongly positively related for rice farmers to the use of methods to control blast and for soybean bean farmers to the probability of using preferred planting techniques. This suggests that learning about the particular conditions of the Center-West region, and how to cope with them, does occur for these farmers, who, recall, are mostly immigrants from the South.

\section{Land quantity and quality}

The total area of land owned by the farmer is unrelated to the adoption of new technology except that wealthier farmers are more likely to use certified rice seed. Topography does seem to be related to the use of preferred practices for soybean farmers. Farmers owning less level land are more likely to plant with preferred methods and use more fertilizer per ha. For upland rice farmers topography has less impact, except for a positive effect on the use of cover fertilizer on farms with steeper slopes. The presence of soil erosion is associated with lower probabilities of using preferred planting methods for soybeans, but is not significantly related to other cultural practices. All of the land quantity and quality effects are robust to the inclusion of cither microregion controls or community infrastructure characteristics.

\section{Regional service availability}

Farmer characteristics, in particular education and possibly local experience, can explain part of the technological adoption choice. They do not, however, explain all the variation in the data and, in fact, the microregion dummies are jointly significant in all the regressions. There is, apparently, a good deal of variation which can be explained by community infrastructure characteristics; we turn next to their impact on the adoption of technology. 
Extension and research availability and quality. We experimented with the inclusion of three EMATER extension characteristics: the number of technicians (or technicians per farm), the proportion with a bachelor degree and their average years of experience. These turn out to be too collinear for any robust results to emerge, although they are jointly significant in a number of cases. Some regularities do appear when only EMATER experience is included in the regressions. Farmers in municipios where EMATER technicians have more experience have higher scores of the soybean technology index and tend to use soybean seeds which are innoculated. These farmers also tend to take soil analyses on their rice plots and use certified rice seed. The effects of an additional year of experience by EMATER technicians is comparable to, and sometimes larger than, the effect of a year of farmer education. Interactions between EMATER experience and farmer education proved not to be significant (not reported). Larger samples may be necessary to test for substitutability or complementarity between these factors.

Fertilizer use is not associated with extension agent experience, nor is using methods to control blast. Also planting soybeans using preferred methods is negatively related to extension agent experience. Still the results do suggest a role for the quality of extension agents, crudely measured, in enhancing the effectiveness of extension agents (Feder and Slade, 1984).

The proportion of farmers (in the microregion) who have contact with EMBRAPA personnel has no effect on soybean practices but does affect upland rice farming practices. In particular the use of soil analyses, cover fertilizer and the quantity per hectare of fertilizer use are all positively related to the extent of EMBRAPA contacts within a region.

The net positive impacts of EMBRAPA and EMATER service availability is quite interesting and potentially important. In unreported probits explaining the probability of a farmer having EMBRAPA or EMATER contacts it was found that being better educated and younger made it more likely to have contacts from EMBRAPA. EMBRAPA also seems to work more in municipios with level land, no radio diffusion programs and with CIBRAZEM storage facilities. EMATER contacts are more likely in areas with low soybean yields and those served by EMATER technicians with more experience.

Other community infrastructure. The other community covariates appear to have little impact on the adoption of these cultivation practices, although there are a few notable exceptions. The existence of a cooperative office in a municipio is positively related to using preferred planting methods for soybeans. The number of banks in a municipio seems to increase the likelihood of taking soil analyses and increasing fertilizer use on soybean plots. The use of innoculated seeds seems to be negatively associated with 
the number of banks. The existence of a radio diffusion program has a positive effect only on the probability of using innoculated seeds but has no impact on any of the other technology practices: radio diffusion seems to be a poor substitute for extension services. The existence of CIBRAZEM storage facilities in a municipio is positively associated with the use of preferred planting practices for soybeans, but tends to be negatively related to fertilizer use, soil analysis and using certified seed for rice. Why is not clear. The existence of CIBRAZEM facilities tends to be in larger centers so there apparently is some unmeasured effect that these areas have on certain farming practices.

\section{Regional agro-climatic conditions}

Agro-climatic conditions are proxied at the municipio level by mean soybean and rice yields, and the standard deviation of those yields over a 7-year period (1979/80-1985/86).

Only a few results emerge for upland rice; more fertilizer (per hectare) and certified seed is more likely to be used in more productive municipios (those with higher mean yields) although the variability of yields has no effect on cultural practices. Soybeans are more likely to be planted with preferred methods in higher yield and higher variance municipios; treated seeds are more likely to be used in better endowed areas.

\section{SUMMARY}

These results suggest that it is possible to identify some of the determinants of the adoption of new technologies and cultural practices, at least within the simple static model outlined in Section 2. Of the factors considered farmer education stands out as being important for both upland rice and soybean technology adoption, as does the quality of extension agents. The former result is consistent with numerous studies in the literature. Rather few studies, however, have examined the impact of extension services in a reduced form model. Of these we are not aware of other studies which explicitly examine the role of the human capital of extension agents.

In sum, better educated farmers are more likely to do soil analyses and use fertilizer on both rice and soy plots, farmers in areas with more experienced EMATER agents are more likely to use treated or certified seeds and use preferred planting methods again on both rice and soybean plots. Relative to soybean farmers rice farmers are more responsive to contact with EMBRAPA personnel and also to higher yields. Farmers with more experience tend to adopt preferred planting methods (on soybean plots) or controls for blast (on rice plots). 
It would be preferable to explain both the extent and process of technological adoption by farmers; this would be possible only with longitudinal data in which each farmer is tracked over several seasons. The results reported above suggest that it may be prudent for both longitudinal and cross section surveys to adopt a broader strategy to data collection on technology adoption than is commonly found. In particular, in addition to technological use data, it would be advantageous to collect information on the human capital and socioeconomic characteristics of farmers, on indicators of land quality and on community level factors. Community-level variables should include both those related to underlying agro-climatic potentials and those related to the availability of relevant farm services. We think that widening the scope of these surveys will have high marginal returns in terms of helping program evaluators and policy makers understand the processes underlying technological adoption.

\section{ACKNOWLEDGEMENTS}

The comments of an anonymous referee, Rodolfo Hoffman, Edgar Lanzar and participants at the EMBRAPA-Yale-IFPRI Workshop on Available Socio-economic Methodologies for the Study of Agriculture, Bento Goncalves, May 1989 are appreciated.

\section{REFERENCES}

Barbosa, M. and Teixeira, S., 1987. Condicoes contextuais e a producao de soja e arroz na regiao centro-oeste. In: Reun. Nac. Pesqui. Arroz, EMBRAPA-CNPAF, Goiania, Brazil. Bhalla, S., 1988. Does land quality matter? J. Dev. Econ., 29: 45-62

Birkhauser, D., Evenson R. and Feder, G., 1989. The economic impact of agricultural extension: a review. Econ. Dev. Cult. Change, 39: 607-650.

Feder, G. and Slade R., 1984. The acquisition of information and the adoption of new technology. Am. J. Agric. Econ., 66: 312-320.

Feder, G., Just, R. and Zilberman, D., 1985. Adoption of agricultural innovations in developing countries: a survey, Econ. Dev. Cult. Change, 33: 255-299.

Homem de Melo, F., 1983. O problema alimentar no Brasil: a importancia dos desequilibrios tecnologicos. Paz e Terra, Rio de Janeiro.

Jamison, D. and Lau, L., 1982. Farmer Education and Farm Efficiency. Johns Hopkins Press for the World Bank, Baltimore, MD.

Patrick, G. and Kehrberg, E., 1973. Costs and returns of education in five agricultural areas of eastern Brazil. Am. J. Agric. Econ., 55: 145-153.

Roe, T. and Graham-Tomasi, T., 1986. Yield risks in a dynamic model of the agricultural household. In: I. Singh, L. Squire and J. Strauss (Editors), Agricultural Household Models: Extensions, Applications and Policy. Johns Hopkins Press for the World Bank, Baltimore, MD.

Sidhu, S. and Baanante, C., 1981. Estimating farm level demand and wheat supply in the Indian Punjab using a translog profit function. Am. J. Agric. Econ., 63: 237-46.

Teixeira, S., 1987. Rice production and technology on a sample of farms in central Brasil (processed).

Welch, F., 1979. Education in production. J. Polit. Econ., 78: 32-59. 